\title{
Challenges in Quantifying a Community's Music Scene
}

\author{
Storm Gloor \\ University of Colorado Denver \\ This paper was presented at the 2018 International Summit of the \\ Music \& Entertainment Industry Educators Association \\ March 22-24, 2018
}

$\underline{\text { https://doi.org/10.25101/18.35 }}$

\section{Abstract}

What music has done for cities like Austin, Texas, Nashville, Tennessee, and Seattle, Washington, is widely known. The economic impact of the various events, institutions, and their respective "scenes" has been most assuredly positive. In addition to the more obvious benefits to a community, what other intrinsic value does a vibrant and sustainable music economy add to a city's economy and well-being? How can it be measured, and how can it be effectively managed? Scholars like Richard Florida and Steven Tepper have expounded on the importance and implications of a healthy creative economy, and the value of the arts in general, both to a community and to the individual. Organizations such as Sound Diplomacy and the Alliance for the Arts in Research Universities have concentrated their efforts on both the recognition of the valuable artistic assets within a community and the activity of effectively supporting and managing those assets. As a part of those assets, music, as a business and as an art form, is certainly a part of the conversation, to varying degrees and depending on the particular community. There are certain practices and initiatives within this segment of the creative economy that go beyond purely monetary impacts that must be part of the measurement of what they contribute to a thriving city.

This research paper identifies these benefits to communities utilizing case studies and identification of successful initiatives while also analyzing the various modes of measuring impact, effectiveness, and vitality of creative economies. The presentation will focus on particular examples and background information on the research and data behind these activities.

Keywords: creative economy, music economy, music scenes, music cities, Richard Florida, Steven Tepper, Colorado music economy, Youth on Record, Illegal Pete's

\section{Introduction}

What's the music economy like where you reside? How "great" is your music scene? Those are two of many questions researchers, scholars, and the popular press address from a myriad of perspectives. There is also the matter of whether one is assessing their local music industry as simply a citizen, a music fan, or a formal stakeholder (policymaker, a music-related business owner, etc.). Indeed, it can be difficult to quantify the viability of a city's music economy. While there are documented statistics and reports that can identify the strength and impact of a music economy to a community, some music-related assets can be difficult to define in terms of impact. ${ }^{1}$ What are some examples of music-related entities or activities within a community for which the impact can be challenging to measure?

\section{Existing Approaches}

A wide range of valuating and ranking music economies has been utilized. Existing data, however generated or interpreted, can provide a basis. There do even exist indexes available to assess music and creative economies.

Many research and scholarly activities have focused on music "scenes" or economies in terms of economic impacts of activities. ${ }^{2}$ The impact of festivals on local economies, for example, have been determined in reports analyzing the Coachella Festival (Indio, California) and Bonnaroo (Manchester, Tennessee), among others. ${ }^{3}$ Research in 2017 found that Austin's annual South by Southwest conference contributed \$349 million to that city's economy in that year alone. $^{4}$

Other impact data can serve as a basis of comparing music scenes, and such rankings are thus open to interpretation. As an example, Richard Florida, well known for his influential book The Rise of the Creative Class, ranked U.S. music scenes by their Metro Music Index. ${ }^{5}$ That index was essentially generated by “...Bureau of Labor Statistics figures on the concentration of musicians and U.S. Bureau of Economic Analysis stats on music and recording industry business establishments. ${ }^{6}$ Though its use extends beyond just the music art form, the Creative Vitality Suite software 
platform, developed by the Western States Arts Federation, can generate a CVI (Creative Vitality Index) to assign values to creative economies. ${ }^{7}$ Developed in cooperation with the Washington State Arts Commission and the Seattle Office of Arts \& Culture, the CVI "helps communities understand and articulate their creative status..."

In contrast to more scholarly and data-tested deliveries, the basis for other rankings and evaluations of music scenes seems far more anecdotal and subjective to various extents. A ranking of the ten best music cities by Livability. com was determined after "we researched other music and travel media rankings with accolades about scenes, venues, and record stores...then we asked for more direction from musicians who've toured the country extensively and gave nominations and tips." A 2015 report on travel site Destination Tips titled "10 Cities with the Hottest Music Scenes in the USA" made no reference to any data or substantiation whatsoever, though the author certainly describes the various cities' music-related activities and attractions, appropriate to the website's focus. ${ }^{10}$

\section{Challenging Examples}

While accurately and reasonably assessing an area's music and/or arts economy in general might be difficult, an exacerbating factor is that the benefit or effect of certain assets within the economy might be even more difficult. A few music-related assets within the state of Colorado might provide examples of such measurement challenges.

Youth on Record (YOR) is a Denver-based non-profit that, "with the help of Colorado's most talented and willing musicians...inspires at-risk youth to see the potential for a better life." 11 YOR meets its commitment to ensure these youth graduate high school and improve their lives through music education and hands-on experiences with the training from professional musicians in the community. ${ }^{12}$ Their recording studio and learning space was purposely established in 2015 in an area and town with dropout and crime rates above state and national averages. ${ }^{13}$ The establishment of YOR not only helped revitalize that neighborhood, but their music service "has inspired over 700 students to increase their high school attendance and grades."14 The organization's success could very well be achieving what Denver Housing Authority Executive Ismael Guerrero described in reference to its opening, when he stated that "if we want to break the cycles of generational poverty, we've got to get that next generation to finish school and not become our next generation of residents living in subsidized housing." 15 Though Youth on Record employs and pays local musicians as instructors, which is measurable data to an extent, the value of what it is accomplishing as part of its key mission of music education for youth in order to improve their opportunities, while certainly good, might be difficult to pre- cisely quantify. ${ }^{16}$ Moreover, any such organization, while also serving a societal good, might easily be classified as a valuable asset when comparing one music city to another.

Illegal Pete's is a "Colorado-based group of quick-service 'Mission Style' burrito restaurants." 17 In recent years the restaurant has established a Starving Artist program, which provides free food to artists traveling through cities where they are located. ${ }^{18}$ They've fed artists such as Elton John, Morrisey, Portugal. The Man, Weezer, and many others through the program. ${ }^{19}$ Though certainly a nice gesture, an advertising opportunity, and likely a good public relations policy, there is no precisely direct benefit to local musicians. Considering that Illegal Pete's would likely be classified as a food establishment and not a music venue, per se, (though locations do include staging and feature local musicians playing) one could argue there's no economic contribution to an entity classified as an arts or music business. Yet surely the Illegal Pete's Starving Artist program should be considered an asset in identifying the caliber of a music city.

After Colorado Amendment 64 was passed in November 2012, the commercial sale of marijuana to the general public began in January $2014 .{ }^{20}$ Speculation arose soon after as to what effect this would have on the music economy in the state. ${ }^{21}$ Within the first year, it was opined that at least in the live music sector there were "a ton of extra shows featuring weed-loving headliners." 22 Snoop Dogg played there "at least four times" in the first year of legalization, for instance. ${ }^{23}$ At the same time, however, rising rents based on "an influx of demand for real estate...due in part to the cannabis industry" was said to have been "hitting musicians particularly hard." ${ }^{24}$ In this case a general determination of the value of the music economy before legalization versus after might say something about the correlation. However, the challenge here is that Colorado's legalization of marijuana could change at any time. ${ }^{25}$ Beyond the challenge of determining causality or the real value of marijuana legalization to music, what, if any, risk factors should be assigned to any assessment of the strength of Colorado's music economy, given that reality?

\section{Conclusion}

These are but a few examples of contributing factors that can make it challenging to accurately quantify a music economy or compare it to any others. Certainly, there are others. In his "Measuring the Cultural Vitality of Scenes: the Music Scene in Chicago" presentation, Lawrence Rothfield, one of the authors of the Chicago Music City report, outlines some characteristics of a scene that required distinct approaches to ascertain. ${ }^{26}$ For example, he and his co-authors developed means to address how "good" the music is, how much variety exists, and the "walkability" of the scene as well. ${ }^{27}$ Even so, the report identifies data points that were tougher to gen- 
erate. ${ }^{28}$ Numbers pertaining to self-employed musicians, for instance, have a limitation when "viewing the music industry as a set of firms" as they do in the report. ${ }^{29}$ Nevertheless, the detailed report was recognized as "impressive...with hard, cold numbers" and was indeed very substantive and informative. ${ }^{30}$

Music scenes are certainly not alone as economic indices that can be difficult to measure. Perhaps it would seem inconsequential to some as subjective opinions about music and arts scenes might simply be good enough for most consumers. However, in determining policies and strategies, data that is as accurate as possible is vital. Perhaps general accuracy is sufficient, understanding the margin of error that could understandably exist. There are perhaps no wrong or right solutions or answers to the intricacies of quantifying a music economy, as long as they make sense. Hopefully it is simply ultimately true that a city and its citizens, regardless of the size and ranking versus others, always want it to be better and strive to do so.

\section{Endnotes}

1. Lawrence Rothfield, "Measuring the Cultural Vitality of Scenes: the Music Scene in Chicago," https://culturalpolicy.uchicago.edu/events/measuring-cultural-vitality-scenes-music-scene-chicago, accessed March 19, 2018.

2. Ibid.

3. Rian Bosse, "Entertaining Businesses: The Impact of Music Festivals," National Center for Business Journalism, 2015. http://businessjournalism.org/2015/06/ entertaining-business-the-economic-impact-of-music-festivals/.

4. David Paul Morris, "Austin's Tourism Cash Cow: SXSW Economic Impact Grows in 2017," Austin Business Journal, September 27, 2017. https://www. bizjournals.com/austin/news/2017/09/27/austins-tourismcash-cow-sxsw-economic-impact-grows.html.

5. Richard Florida, "The Geography of America's Music Scenes," Citylab, August 6, 2012. https://www. citylab.com/design/2012/08/geography-americas-music-scenes/2709/.

6. Ibid.

7. "Creative Vitality Suite," CVSuite.org, accessed June 28, 2018. https://cvsuite.org/about-2/.

8. John M. Eger, "Taking the Creative and Economic Pulse of the City," Huffington Post, June 9, 2014. https:/www.huffingtonpost.com/john-m-eger/the-creative-vitality-ind b 5340918.html.

9. “2012 10 Best Music Cities," Livability, accessed March 17, 2018. https://livability.com/top-10/culture/10-best-music-cities/2012.

10. Tessa Riley, "10 Cities with the Hottest Music Scenes in the USA," Destination Tips, May 9, 2015. https:// www.destinationtips.com/destinations/10-cities-withthe-hottest-music-scenes-in-the-usa/?listview=all.

11. "Youth on Record," accessed June 28, 2018. https:// www.youthonrecord.org/.

12. Ibid.

13. Scott Beckman, "Youth On Record - Inspiration Through Music," FiveFifty, July 28, 2015. https:// www.fivefifty.com/youth-on-record/.

14. Ibid.

15. Tim Wenger, "Revisiting Past Work: Denver Housing Authority, Local Charity Work to Create Music Studio For Under-Served Youth", Colorado Music Buzz, May 2015. https://www.timwenger.net/single-post/2016/11/20/Revisiting-past-work-DenverHousing-Authority-Local-Charity-Work-To-CreateMusic-Studio-For-Under-Served-Youth.

16. Scott Beckman, "Youth On Record - Inspiration Through Music," FiveFifty, July 28, 2015. https:// www.fivefifty.com/youth-on-record/. 
17. "Illegal Pete's," Wikipedia, accessed June 28, 2018. https://en.wikipedia.org/wiki/Illegal_Pete $\% 27 \mathrm{~s}$.

18. Dave Herrera, "Illegal Pete's to Feed Starving Artists Coming Through Denver," Westword, September 21, 2010. http://www.westword.com/music/illegalpetes-to-feed-starving-artists-coming-through-denver-5715069.

19. "Starving Artists," Illegal Pete's, accessed March 18, 2018. http://illegalpetes.com/starvingartists/.

20. "Colorado Amendment 64," Wikipedia, accessed June 27, 2018. https://en.wikipedia.org/wiki/Colorado Amendment 64 .

21. Steve Knopper, "How Colorado's New Pot Laws Will Affect the Local Concert Industry", Rolling Stone, January 6, 2014.

22. Westword Staff, "Eight Ways Legal Weed Has Changed Colorado's Music Scene," Westword, December 19, 2014.

23. Ibid.

24. Ibid.

25. Scott Mclean and Sara Weisfeldt, "Colorado Governer Won't Rule Out Banning Marijuana Again. Here's Why," CNN, April 20, 2018.

26. Lawrence Rothfield, "Measuring the Cultural Vitality of Scenes: the Music Scene in Chicago," YouTube, accessed March 19, 2018. https://www.youtube.com/ watch? $\mathrm{v}=$ pnvv4aCoMD0\& $\mathrm{t}=1874 \mathrm{~s}$.

27. Lawrence Rothfield, Don Coursey, Sarah Lee, Daniel Silver, and Wendy Norris, Chicago Music City: A Report On the Music Industry in Chicago (Chicago: The Cultural Policy Center at the University of Chicago, 2007). http://www-news.uchicago.edu/releases/08/ pdf/080122.music.pdf.

28. Ibid.

29. Ibid.

30. Jim DeRogatis, "The Chicago Music Commission is talking a lot, but is it doing anything?" jimdero.com, January 25, 2008. http://jimdero.com/News2008/Chicagomusiccommission.htm.
Storm Gloor, MBA, is an associate professor in the department of Music and Entertainment Industry Studies in the College of Arts \& Media at the University of Colorado Denver. He teaches courses in music marketing, the future of the music business, and other subjects. He has presented instructional sessions at numerous events and programs, including the education-focused portion of South By Southwest (SXSW.edu), South By Southwest Music, the Denver Music Summit, and the Underground Music Showcase. He is the current president of MEIEA.

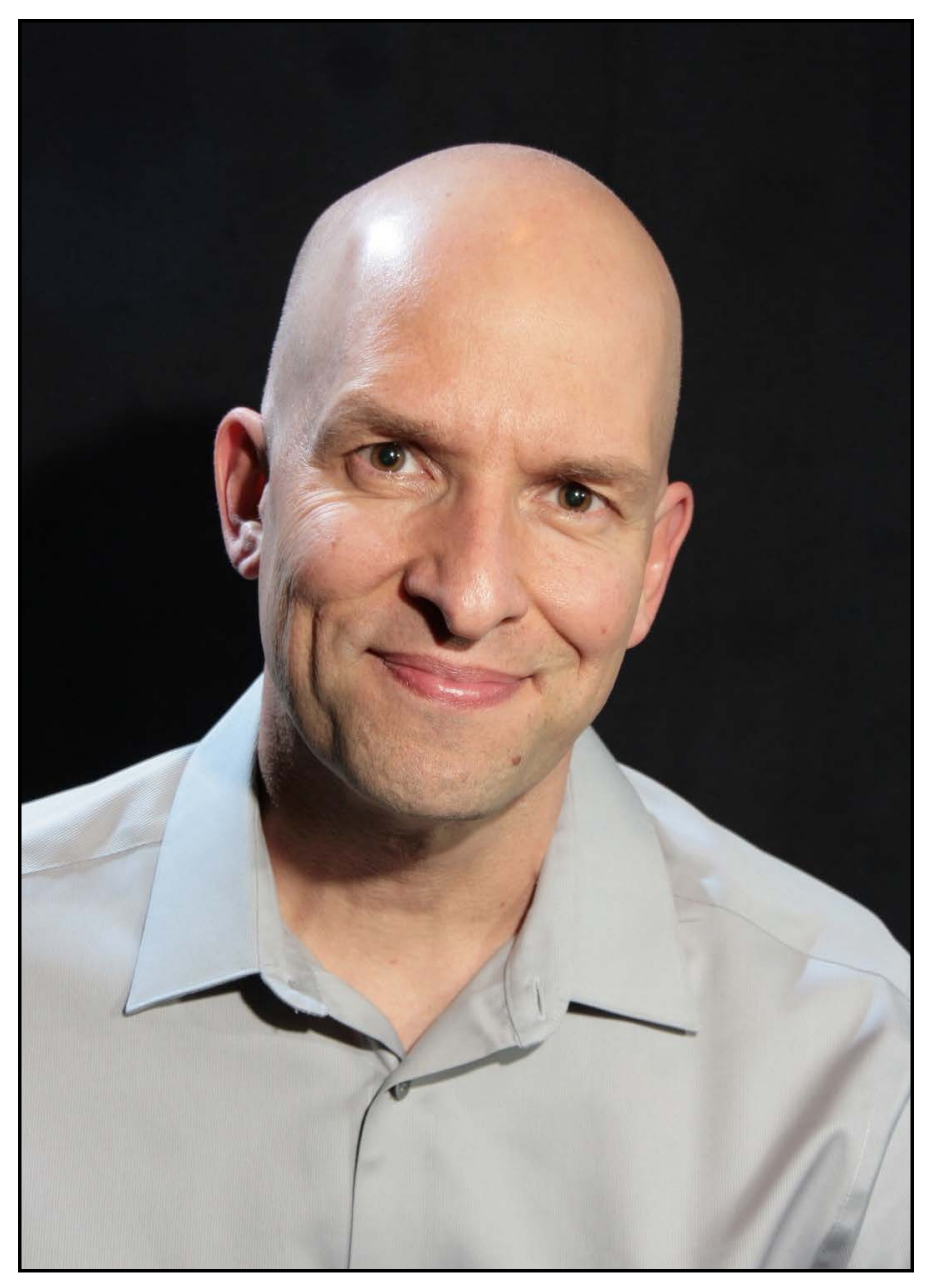




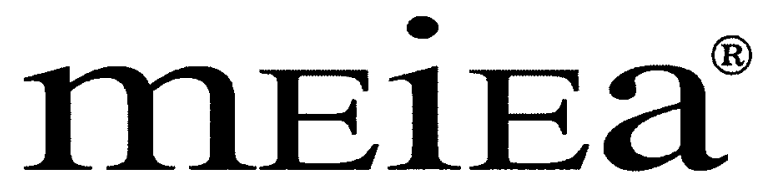

MUSIC \& ENTERTAINMENT INDUSTRY

EDUCATORS ASSOCIATION

\section{PROCEEDINGS OF THE \\ 2018 INTERNATIONAL SUMMIT}

OF THE

\section{MUSIC \& ENTERTAINMENT INDUSTRY EDUCATORS \\ ASSOCIATION}
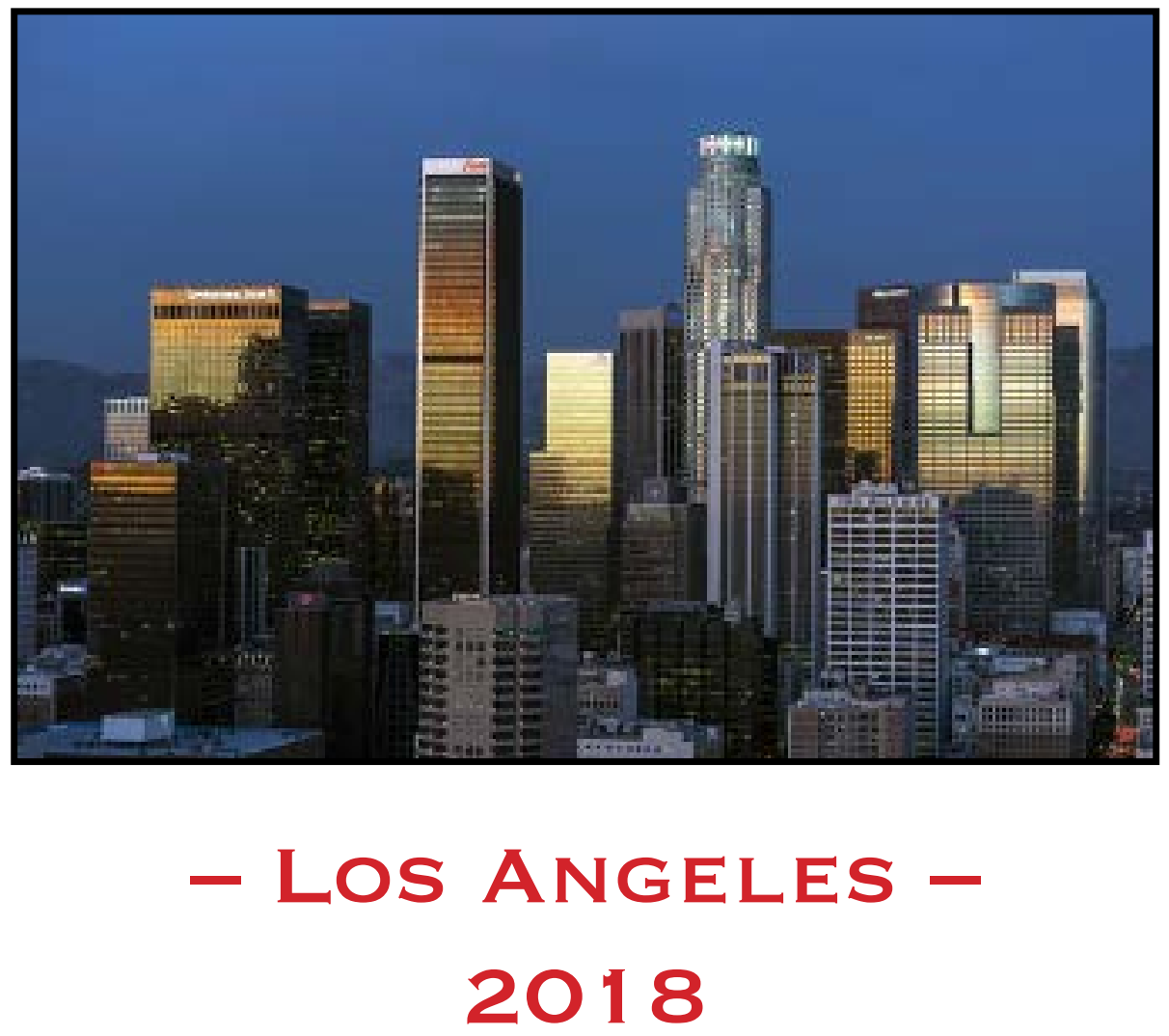

March 22 - 24, $2018 \cdot$ Embassy Suites by Hilton - Los Angeles/Glendale 